\title{
Knowledge Representation in Map Collections for Information Retrieval Systems
}

\author{
by WIESLAW BABIK
}

In this article, I will deal with the issue of the knowledge representation ${ }^{1}$ about maps kept in libraries or available through Internet from the viewpoint of information retrieval. Representation of knowledge belongs to those fields, which have undergone dynamic change in recent decades. The interest it not only raises among specialists, but also among librarians and information scientists indicates the viability of this field of study. Many scholars conduct research in the respective areas. Articles on the subject related to the documentation are also published. The knowledge of the contents of a map collection is represented in the information retrieval system by metainformation kept in databases, which also perform regular retrieval process. Indeed, we are talking about the problems of access to the contents of map collections through respective information retrieval systems requiring such a system of map description and formal and subject cataloguing which would allow for searching maps relevant to the needs of their users. Using documentation terminology, first of all we mean the issue of information retrieval languages designed for such collections and primarily the method of representing knowledge for the needs of such materials classification which so far may be one of the basic tools of map collection organisation. ${ }^{2}$

The application of computer technology in libraries causes that the previously used organisation and representation of knowledge is changing. Thus we need a proposal for a conception of knowledge organisation and representation concerning map collections in the conditions of using computer technology for information retrieval, access and dissemination. ${ }^{3}$

In the 20th century, we have been observing the increase of information on maps. This concerns descriptions, statistics, and spatial information (aerial photographs or satellite images) which caused the expansion of the scope of interest on the part of both geographers and cartographers. Also the scope of map users has increased. Maps contain a specific type of knowledge. For the needs of knowledge representation, a special artcial language has been created. It is called map language, while for the needs of representing the 
knowledge of maps, special retrieval languages are designed, including basically classification type languages. Also the natural language in its metafunction is a tool of knowledge representation on the map and about the map. The analysis of representation of cartographic information by use of linguistic methods is an interesting perspective for research.

Nowy Leksykon PWN [6] gives the following definition of the term knowledge: 1. in narrow meaning: a body of reliable information about reality, including the skills of using it; 2 . in broad meaning: any collection of information (in our case, information on maps) with cognitive and/or practical value (in our case, usability in the information retrieval process). The same Dictionary also gives a definition of the term information. It is an abstract object which can be recorded in its encoded form (on information carriers), transmitted, processed with computer software and used to control equipment. However, the information collection, also called retrieval collection, is a collection of maps in the case under discussion constituting a basis for information selection. Practically, the term information collection refers mainly to the collection of derivative maps [8, p. 175], i.e. those containing metainformation about maps as a result of a formal and/or subject description of them. The derivative document is for instance a catalogue card, catalogue description, abstract, documentation analysis, or bibliography, while information collections are e.g. catalogues or databases.

Consider the advantages and disadvantages of maps in the context of two main questions: to what extent they represent reality, or perceived reality, and thereby influence decision making, and how do they communicate? Consider map types, their storage potential and role as models. Disadvantages are looked at in terms of distortion, specificity to a point in time, and selectivity. Maps are a vital aid in understanding the complex reality of the physical and human landscape, but, like any model, they must be used with caution. For a librarian to act successfully as a liaison between the cartographic data depicted on a map and the user, he or she must be familiar with some basic cartographic concepts: map type, scale, position projection etc. [5].

Maps being the most important type of cartographic materials ${ }^{4}$ are mathematically generalised representations of the surface of Earth or other planets and heavenly bodies on the plane with images and signs showing the status, distribution and connections among selected objects and/or natural, social, economic, cultural and other phenomena described in accordance with the application of a given map. In the older topography of the Earth and other planets, special attention was devoted to depicting various properties of the ground surface which would allow for a detailed description of the world and satisfy information needs of the contemporary map users. Together with the increase of the significance of thematic cartography, the emphasis was shifted 
Knowledge Representation in Map Collections for Information Retrieval Systems

from topographic or geographic presentations to thematic or subject information. Modern maps allow for the presentation of specific data and phenomena ordered in space and structure.

The mathematically determined map structure establishes a strict functional dependence between the co-ordinates of point on the surface of the Earth and the co-ordinates of the same points on the map surface. The transfer from the physical surface of the Earth to its representation on the plane is possible owing to cartographic mapping which takes into account and defines the character, size and distribution of transformation distortions of the object found on the surface of the Earth. A property of each cartographic transformation is, for example, the distortion expressed by scale diversity. The application of cartographic transformations allows us to draw from maps data concerning real location, sizes and shapes of the objects being represented. This process of selection and generalisation of such objects and phenomena is called cartographic generalisation.

According to A. M. Berlant [3], maps as cartographic representations have basic properties of models, including among other things abstraction, generalisation, selection of the object's features and synthesis comprehensive presentation of the phenomena which occur in isolation. ${ }^{5}$ C. Steuer [9] enumerated the following three properties of maps as models: transformation [representation of relationships and properties of the original], reduction [maps reduce relationships and original properties taking into account only those which are essential for the author or user], and pragmatics [maps are substitutes of originals]. Thus, the map is an information model, i.e. an information copy of the piece of reality at a given level of knowledge.

From the viewpoint of information retrieval, the following distinctive features of maps (in non-hierarchical order) are important:

1. territory;

2. theme;

3. time (date of edition; date of the map situation);

4. scale;

5. author;

6. description language;

7. title;

8. format (size);

9. circulation; 
10. presentation method;

11. manner of use and storage;

12. application;

13. medium;

14. colours;

15. orientation;

16. transformation;

17. map graticule;

18. geographic co-ordinates;

19. accessibility;

20. rendering technique;

21. printing technique [2].

These features affect the relevance in the process of searching for maps and that is why they should be taken into account in the information concerning the map form and content. They are related to the editorial process, i.e. content organisation and method of its presentation, rendering technique and type of material. It also refers to the cartographic transformation, map graticule, orientation and elements of the bibliographic description. These items, although being exponents of formal relevance, affect the semantic relevance, since they may determine not only the method of transformation, but also the scope of the knowledge of reality being transformed, as well as the degree of information reduction and types and extension of distortions occurring during the editorial process.

The distinctive features of maps may constitute retrieval elements in the process of cartographic information retrieval. The existing standards of bibliographic description use a very limited scope of means of knowledge representation on maps in comparison to the existing possibilities. This often causes unnecessary loss of essential information which might be useful for satisfying the needs of map users. The basic features of maps, i.e. the territory, subject matter, date of issue, format, type of map graticule and transformation and physical features constitute a basis of the texts in maps containing cartographic information which is complex and multi-dimensional in nature [4].

The level of maps description is primarily created by the elements of the bibliographic description. They determine the scope of information identifying maps. In addition to national standards, there is also an international 
Knowledge Representation in Map Collections for Information Retrieval Systems

standard of bibliographic description for cartographic materials prepared by IFLA in 1977 (revised ed. 1987, new revision pending). This standard is abbreviated as $\operatorname{ISBD}(\mathrm{CM})$; International Standard of Bibliographic Description for Cartographic Materials. The data included in the title characterise maps not only as documents, but also pass information about map as a text [1]. In the case of $\operatorname{ISBD}(\mathrm{CM})$, the nature of data also depends on the decisions of the indexer who determines the level of description details depending on the needs of potential users.

Cartographic materials can be used in all stages of information supply, because cartography presents different types of spatially structured information in a well-oriented way and offers important expedients when data are supplied in great quantity. Representation of information on the map can be described as plane network, although being three-dimensional. The collection of maps on electronic carriers can be distributed. As to its structure - it can be hypermedial, content - multimedial or traditional, access - available on-line or through the Internet (databases or WWW). Maps can be either parts of encyclopaedias, books, computer games, or published in traditional formats.

Map collections as a type of special collections require a separate method of processing. Since the beginning of their existence, i.e. the beginning of the 20th century, attempts have been made to standardise the methods of both formal and content processing. Many regulations and instructions were adopted. Neither of them is, however, mandatory for all the libraries having separate map collections. Practically, larger libraries use their own internal regulations taking into account the character of the particular collection. We should add that digital map collections have been made in the form of computer files which also have to be properly described for retrieval purposes, i.e. classified and catalogued. In many libraries, automation of map collection processing and providing access has been implemented.

The scope of problems related to the classification of cartographic materials is broad and concerns some basic matters. First of all, we should specify a lack of uniform classification criteria. Classification is the most common tool of map collection organisation. It should be closely related to the pro-perties of cartographic materials. Under the current classification systems for cartographic materials, geographic criteria have been adopted as the basis of categorisation. However, outside the geographic area the subject matter seems to be the best identifying property of cartographic materials [1].

Knowledge about map collection is usually contained in databases these days. In addition, such information is available from distributed databases or through the Internet. 
The issues mentioned in this article concern the selected problems of organisation and representation of knowledge about map collection in the context of map retrieval systems in libraries. Representation of knowledge occurs here at the level of cartographic information when we perceive maps as the source of information, and at the level of its description when we perceive them from the viewpoint of information about maps and collections of such materials kept in libraries or networks. This is in fact either the representation of information or representation of metainformation. The application of the cognitive paradigm with reference to map collections allows us to perceive them not from the viewpoint of transformation in language, (e.g. the type of classification or knowledge of reality) but in the terms of the more fashionable issues of knowledge organisation and representation.

\section{REFERENCES}

1 Knowledge is here understood as information examined in relation to the cognitive aim of the library user. The term knowledge representation refers to the issues of presentation of knowledge about reality in the manner understood by the computer.

2 It wishes to contribute to an intensified and accelerated exchange of experiences in this field [2]. This paper is based first of all on my research conducted in 1988-1991 for my dissertation on The Applying of the Facet Model Lexical Material Organisation for Classification of Cartographic Materials presented at the Faculty of Neophilology of the University of Warsaw. Warsaw 1991, 354 p. [Published as a series of articles in „Zagadnienia Informacji Naukowej” (Eng. „Problems of Information Science”)].

3 In cartographic literature, we notice a clear shift in the cartographers' interest from the map preparation towards the issues concerning the use of maps. This concerns both methods of using maps at the scientific and general levels. At the same time, we feel stronger and stronger a lack of both theoretical considerations and general concepts which would order the present cartographic knowledge and provide map users with the knowledge necessary to correct interpretation of map contents and their identification. Such a conception may constitute an information approach from the viewpoint of knowledge representation. The information approach consists in viewing maps from the position of their functions. That is why it is closer to librarians. The map is treated as a means of passing chorological information (i.e. information pertaining to the geographical extent or limits of anything) between the cartographer (the author of the map) and the reader. In this approach, which has been developed basically within the Cartographic Representation Commission of the Inter- 
Knowledge Representation in Map Collections for Information Retrieval Systems

national Cartographic Association, the information theory concepts and arrangements were admitted quite liberally. They were, however, verified with time which brought the development of new interesting conclusions and research areas. We should mention that this direction has both ardent followers and determined opponents. A positive aspect of this approach is certainly an indication of a possibility to analyse maps as information carriers, or the issue of optimum cartographic sign, which is essential from the viewpoint of library and information science and supporting linguistic conceptions, as well as the indication of the undecided dispute concerning the essence of the map language.

4 Basic cartographic materials collected in libraries include maps, plans, atlases, globes and aerial and satellite photographs. These types of materials are different in the manner of representing the reality in the form of threedimensional models containing qualitative and quantitative characteristics of objects, phenomena or processes. Particular types of cartographic materials have characteristic features called distinctive features. Presently, maps constitute about $95 \%$ of cartographic materials.

5 See the article: C. Board: Maps as Models. [In:] Models in Geography. Ed. R. J. Chorley, P. Hagget. London, New York 1967.

\section{BIBLIOGRAPHY}

[1] Babik, W.: Materialy kartograficzne jako zródlo informacji. „Zagadnienia Informacji Naukowej" 1992 No 1 (59), pp. 3-36.

[2] Babik, W.: Pragmatic model of lexical material organization for faceted classification of cartographic materials. Paper presented at the 7 th Conference of LIBER MAPLIBRARIANS (Ligue des Bibliotheques Europeennes de Recherche. Groupe de Cartothecaires), Paris: Bibliotheque Nationale and Institut Geographique National 24-28 September 1990 on the topic „New Technologies and Their Impact on Mapcuratorship”. Kraków 1993 (PRACE. STUDIA. PRZYCZYNKI, 2).

[3] Berlant, A. M.: O swojstwach kartograficzeskoj modieli. „Izwiestia Wsiesojuznogo Gieograficeskogo Obszczestwa" Vol. 105, 1973 No 4, pp. 327332.

[4] Charre, J. P.: Essai d'Analyse des Documents geo-iconographiques. Paper presented on IFLA General Conference, Paris 1989. [In:] Conference Proceedings. Paris 1989, pp. 49-61. 
[5] Kloti, T.: Aufstellung einer Kartensammlung in einer Fachbereichsbibliothek. [In:] Menzler R. (Hrsg.): Anwendungen in der Klassifikation. Bd I. Proceedings der 8. Jahrestagung der Gesellschaft für Klassifikation 10.-13. April 1984. F.a M.: Indeks Verlag 1985, pp. 124-130 (Studien zur Klassifikation, Bd 14).

[6] Nowy Leksykon PWN. Warszawa: Wydawnictwo Naukowe PWN 1998.

[7] Slownik encyklopedyczny jezyków $i$ systemów informacyjnowyszukiwawczych. Red. nauk. B. Bojar. Warszawa: Wydawnictwa Uniwersytetu Warszawskiego 1993.

[8] Steuer, C.: Theoretische Grundlagen der kartographischen Kommunikation. Einige Aspekte und theoretische Grundlagen zur systematischen Darlegung und Erklärung des Wesens, der Bedeutung und der Problematik der kartographischen Kommunikation unter besonderer Berücksichtigung außerkartographischer Grundlagendisziplinen. Wien: Institut für Geographie der Universität Wien, 1981 (Beiträge aus dem Seminarbetrieb und Arbeitsbereich des Ordinariats für Geographie und Kartographie; Band 13).

Wieslaw Babik

Institute of Librarianship and Information

The Jagiellonian University

Ul. Golebia 16

31-007 Kraków, Poland

ibabik@ filon.filg.uj.edu pl 